DOI https://doi.org/10.30525/978-9934-26-113-8-11

\title{
CLINICAL EXAMINATION DATA OF PATIENTS WITH DESQUAMATIVE GLOSSITIS COMBINED WITH RHEUMATOID ARTHRITIS
}

\author{
Povsheniuk A. V. \\ Candidate of Medical Sciences, \\ Associate Professor at the Therapeutic Dentistry Department \\ National Pirogov Memorial Medical University \\ Shinkaruk-Dykovytska M. M. \\ Doctor of Medical Sciences, Professor, \\ Head of the Therapeutic Dentistry Department \\ National Pirogov Memorial Medical University

\section{Aleksyeyenko N. S.} \\ Senior Lecturer at the Therapeutic Dentistry Department \\ National Pirogov Memorial Medical University \\ Gadzhula N. G. \\ Candidate of Medical Sciences, \\ Associate Professor at the Therapeutic Dentistry Department \\ National Pirogov Memorial Medical University
}

\section{Pilipiuk O. Yu.}

Candidate of Medical Sciences, Assistant at the Therapeutic Dentistry Department

National Pirogov Memorial Medical University

Vinnytsya, Ukraine

Relevance: In the practice of a dentist, patients with desquamative glossitis are quite common. Moreover, there is a relatively high incidence of the oral mucosa and red border of the lip's diseases, combined with diffuse connective tissue lesions, in particular with rheumatoid arthritis [3 p. 12; 4 p. 3]. However, insufficient attention is paid to their diagnosis and selection of adequate therapy and prevention, which is associated with a variety of clinical manifestations of combined systemic lesions. 
The development of desquamative glossitis is associated with primary lesions of the microcirculatory tract due to immunopathological reactions that lead to generalized disorganization of connective tissue and secondary changes in the epithelium and the mucous membrane of the tongue [5 p. 154; 6 p. 29]. Scientific studies have found similar changes in rheumatoid arthritis in other organs and systems $[1$ p. 30; 2 p. 5]. Therefore, the influence on the condition of the oral mucosa has not been excluded.

Objective: to establish the features of the clinical course of desquamative glossitis with concomitant rheumatoid arthritis.

Materials and methods: In order to study the nature of the clinical course of desquamative glossitis combined with rheumatoid arthritis, a survey of 25 patients with this pathology, aged from 42 to 61 years, was performed.

The clinical examination included interviewing, studying the anamnesis of the disease and the patient's life, conducting basic research methods.

Examination of patients revealed complaints of discomfort, burning, tightness and dryness of the oral mucosa. Pain was noted in the area of the tongue when eating and talking. While collecting the anamnesis, we took into account the duration of the underlying disease and the relationship between the occurrence of complaints from the oral cavity and its dynamics, the presence of recurrences and remission. The nature of previous treatment and its effectiveness were clarified. The skills of hygienic care of the oral cavity were taken into account as well.

Transferred and concomitant dental and somatic diseases were detected, as well as the presence of bad habits.

Examination determined the presence of pathological changes in the mucous membrane of the mouth, tongue, lips, palate. We conducted determination of the condition of the teeth, dentition and occlusion. Attention was paid to the presence of orthopedic structures in the oral cavity.

All examined patients underwent a visual assessment of the condition of the oral mucosa, which, according to WHO recommendations, was determined sequentially by topographic areas.

When conducting a clinical study, the required minimum number of respondents was determined using the Glen method. The evaluation of the obtained results was carried out on the basis of determining the relative value of the indicator. For statistical data processing we used a non-parametric method - the criterion $\chi^{2}$.

Results: Dental examination of patients with desquamative glossitis in combination with rheumatoid arthritis revealed no complaints in $12.0 \pm 3.5 \%$ of patients. $64.0 \pm 9.6 \%$ of patients paid attention to the unusual appearance of the tongue. However, the majority of patients (22 patients out of 25 , which was $88.0 \pm 6.5 \%$ ) complained of changes and lesions of the oral mucosa. 
Patients noted a constant change in the size and location of the affected areas of the tongue surface. The main complaints were dry mouth, which was noted in 14 patients $(56.0 \pm 9.9 \%)$, pain in the tongue - in $17(68.0 \pm 9.3 \%)$, burning - in $15(60,0 \pm 9.8 \%)$, bad breath - in $14(56.0 \pm 9.9 \%)$ and taste disturbance - in $18(72.0 \pm 9.0 \%)$. Subjective sensations (from burning to pain) were more often disturbed when eating. The correspondence of the localization of unpleasant sensations to the areas of desquamation, as well as the reduction of their intensity or disappearance during epithelialization of the affected areas indicate that the subjective sensations are largely due to the desquamation of the epithelium. The nature and severity of these complaints depended on the duration of concomitant rheumatoid arthritis: within 2 years - in $40.0 \pm 9.8 \%$ of patients, $3-4-$ in $60.0 \pm 9.8 \%$. The frequency of visits to dentists in the anamnesis remained low $-24.0 \pm 7.5 \%$. The vast majority of patients used keratoplasty ointments, but no noticeable improvement was distinguished. Combinations with diseases of the gastrointestinal tract were found in 7 (28.0 $\pm 9.0 \%)$ patients, with anemia - in $5(20.0 \pm 8.0 \%)$.

Objective examination of patients with desquamative glossitis combined with rheumatoid arthritis revealed edema $(36.0 \pm 9.6 \%)$ and hyperemia with cyanosis of the oral mucosa $(24.0 \pm 7.5 \%)$. Impressions of teeth on the lateral surface of the tongue were determined in $72.0 \pm 9.0 \%$ of cases (18 people), plaque on the dorsal surface of the tongue - in $80.0 \pm 8.0 \%$ (20 patients). On the back of the tongue there are areas of desquamation and atrophy of filamentous papillae of round shape with clear boundaries, surrounded by a narrow rim of the desquamated zone of hyperkeratosis, which rises above the level of the surface of the tongue. Changes in the tongue were combined with the phenomena of its folding in 9 patients.

Conclusion: The results of our clinical examination of patients confirm the aggravating nature of the concomitant pathology on the development of desquamative glossitis. In addition, the abundant microflora in the unsanitized oral cavity, decreased salivation, chronic injuries contribute to increased inflammation and the appearance of subjective sensations in patients with desquamative glossitis.

The condition of the oral mucosa largely depended on the nature, duration and severity of the comorbidity.

\section{References:}

1. Assil Saleh. Rheumatoid arthritis: disease pathogenesis. Johns Hopkins advanced studies in norsing. 2008. Vol. 6 (2). P. 26-31.

2. Hans Ulrich Scherer, Thomas Häupl, Gerd R. Burmester. The etiology of rheumatoid arthritis. Journal of Autoimmunity. 2020. № 110. P. 1-15. 
3. Roberta Gualtierotti, Angelo Valerio Marzano, Francesco Spadari, Massimo Cugno. Main Oral Manifestations in Immune-Mediated and Inflammatory Rheumatic Diseases. Journal of Clinical Medicine. 2019. № 8. P. 1-19.

4. Robert JR Reilly, William Johnston, Shauna Culshaw. Autoimmunity and the Oral Cavity. Current Oral Health Reports. 2019. № 6. P. 1-8.

5. Банченко Г. В., Максимовский Ю. М., Гринин В. М. Язык «зеркало» организма : клиническое руководство для врачей. Москва : ЗАО «Бизнес Центр «Стоматология», 2000. 407 с.

6. Модина Т. В., Шумський А. В., Мамаева Е. В., Железняк В. А. Диагностика и лечение различных форм десквамативного глоссита. Becтник современной клинической медициины. 2010. Т. 3, № 1. С. 26-32.

DOI https://doi.org/10.30525/978-9934-26-113-8-12

\title{
ORAL MANIFESTATION OF PATIENT WITH COVID-19: CASE REPORT OF NECROTIZING ULCERATIVE GINGIVITIS
}

\author{
Samoilenko A. V. \\ Doctor of Science in Medicine, Professor, \\ Head of the Department of therapeutic dentistry \\ Dnipro State Medical University \\ Oryshchenko V. Yu. \\ Candidate of Medical Sciences, \\ Associate Professor at the Department of therapeutic dentistry \\ Dnipro State Medical University \\ Strelchenia T. N. \\ Candidate of Medical Sciences, \\ Associate Professor at the Department of therapeutic dentistry \\ Dnipro State Medical University \\ Dnipro, Ukraine
}

Coronavirus disease 2019 (COVID-19) is a respiratory illness caused by the severe acute respiratory syndrome coronavirus 2 (SARS-CoV-2). This infection has a broad spectrum of presentations that can range from asymptomatic disease to fatal acute respiratory distress syndrome[1, p. 143]. 